This document is the accepted manuscript version of the following article:

Brack, W., A7tenburger, R., Schüürmann, G., Krauss, M., López Herráez, D., van Gi1s, J., ... de Aragão Umbuzeiro, G. (2015). The SOLUTIONS project: challenges and responses for present and future emerging pollutants in land and water resources management. Science of the Total Environment, 503-504, 22-31.

https://doi.org/10.1016/j.scitotenv.2014.05.143

This manuscript version is made available under the CC-BY-NC-ND 4.0 1icense http:// creativecommons.org/licenses/by-nc-nd/4.0/

\title{
SOLUTIONS for present and future emerging pollutants in land and water resources management
}

Werner Brack ${ }^{\mathrm{a}}$, Rolf Altenburger ${ }^{\mathrm{a}}$, Gerrit Schüürmann ${ }^{\mathrm{a}}$, Martin Krauss ${ }^{\mathrm{a}}$, David López Herráez ${ }^{\mathrm{a}}$, Jos van Gils ${ }^{\mathrm{b}}$, Jaroslav Slobodnik ${ }^{\mathrm{c}}$, John Munthe ${ }^{\mathrm{d}}$, Bernd Manfred Gawlik ${ }^{\mathrm{e}}$, Annemarie van Wezel ${ }^{\mathrm{f}}$, Merijn Schriks ${ }^{\mathrm{f}}$, Juliane Hollender $^{\mathrm{g}}$, Knut Erik Tollefsen ${ }^{\mathrm{h}}$, Ovanes Mekenyan ${ }^{\mathrm{i}}$, Saby Dimitrov ${ }^{\mathrm{i}}$, Dirk Bunke, Ian Cousins ${ }^{\mathrm{k}}$, Leo Posthuma, Paul J. van den Brink ${ }^{\mathrm{m}}$, Miren López de Alda $^{\mathrm{n}}$, Damià Barceló ${ }^{\mathrm{n}}$, Michael Faust ${ }^{\mathrm{o}}$, Andreas Kortenkamp $^{p}$, Mark Scrimshaw ${ }^{p}$, Svetlana Ignatova ${ }^{q}$, Guy Engelen ${ }^{r}$, Gudrun Massmann ${ }^{\mathrm{s}}$, Gregory Lemkine ${ }^{\mathrm{t}}$, Ivana Teodorovic ${ }^{\mathrm{u}}$, Karl-Heinz Walz ${ }^{\mathrm{v}}$, Valeria Duliow ${ }^{\mathrm{w}}$, Michiel T.O. Jonker ${ }^{\mathrm{x}}$, Felix Jäger ${ }^{\mathrm{y}}$, Kevin Chipman ${ }^{\mathrm{z}}$, Francesco Falciani ${ }^{\text {aa }}$, Igor Liska ${ }^{\text {bb }}$, David Rooke ${ }^{\mathrm{cc}}$, Xiaowei Zhang ${ }^{\text {dd }}$, Henner Hollert ${ }^{\mathrm{ee}}$, Branislav Vrana ${ }^{\mathrm{ff}}$, Klara Hilscherova $^{\text {ff }}$, Kees Kramere ${ }^{\text {gg }}$, Steffen Neumann ${ }^{\text {hh }}$, Ruth Hammerbacher ${ }^{\mathrm{ii}}$, Thomas Backhaus ${ }^{\mathrm{jj}}$, Juliane Mack ${ }^{\mathrm{kk}}$, Helmut Segner ${ }^{11}$, Beate Escher ${ }^{\text {mm,a }}$, Gisela de Aragão Umbuzeiro ${ }^{\text {nn }}$

${ }^{a}$ Helmholtz Centre for Environmental Research UFZ, Leipzig, Germany

${ }^{\mathrm{b}}$ Foundation Deltares, Delft, The Netherlands

${ }^{\mathrm{c}}$ Environmental Institute, Koš, Slovak Republic

d IVL Swedish Environmental Research Institute, Gothenburg, Sweden

e Institute for Environment and Sustainability -IES- of the European Commission's Joint Research Centre JRC, Ispra, Italy

${ }^{\mathrm{f}}$ KWR Watercycle Research Institute, Nieuwegein, The Netherlands

${ }^{\mathrm{g}}$ Swiss Federal Institute of Aquatic Science and Technology Eawag, Dübendorf, Switzerland

${ }^{\mathrm{h}}$ Norwegian Institute for Water Research NIVA, Oslo, Norway

${ }^{\mathrm{i}}$ Laboratory of Mathematical Chemistry - Asen Zlatarov University, Bourgas, Bulgaria

${ }^{j}$ Oeko-Institut e.V. - Institute for Applied Ecology, Freiburg, Germany

${ }^{\mathrm{k}}$ Stockholm University, Stockholm, Sweden

${ }^{1}$ National Institute for Public Health and the Environment RIVM, Bilthoven, The Netherlands

${ }^{m}$ ALTERRA, Wageningen, The Netherlands

${ }^{\mathrm{n}}$ Agencia Estatal Consejo Superior de Investigaciones Científicas CSIC, Barcelona, Spain

${ }^{\circ}$ Faust \& Backhaus Environmental Consulting, Bremen, Germany

${ }^{\mathrm{p}}$ Brunel University, Institute for the Environment, London, United Kingdom

${ }^{\mathrm{q}}$ Brunel University, Institute for Bioengineering, London, United Kingdom

${ }^{\mathrm{r}}$ Flemish Institute for Technological Research VITO, Mol, Belgium

${ }^{\mathrm{s}}$ Carl von Ossietzky University, Oldenburg, Germany

${ }^{\mathrm{t}}$ WatchFrog, Evry, France

${ }^{\mathrm{u}}$ University of Novi Sad, Novi Sad, Serbia

${ }^{v}$ MAXX Mess- und Probenahmetechnik GmbH, Rangendingen, Germany

${ }^{\mathrm{w}}$ Institut National de l'Environnement Industriel et des Risques INERIS, Verneuil-en-Halatte, France

${ }^{\mathrm{x}}$ Utrecht University, Utrecht, The Netherlands

${ }^{\mathrm{y}}$ Synchem UG \& Co. KG, Felsberg / Altenburg, Germany

${ }^{\mathrm{z}}$ University of Birmingham, Birmingham, United Kingdom

${ }^{\text {aa }}$ University of Liverpool, Liverpool, United Kingdom

${ }^{\mathrm{bb}}$ International Commission for the Protection of the Danube River ICPDR, Vienna, Austria

${ }^{c c}$ Dynamic Extractions, Slough, United Kingdom

${ }^{\mathrm{dd}}$ State Key Laboratory of Pollution Control and Resource Reuse \& School of the Environment, Nanjing University, Nanjing, P.R. China

${ }^{\text {ee }}$ RWTH Aachen University, Aachen, Germany

${ }^{\mathrm{ff}}$ Masaryk University - Research Centre for Toxic Compounds in the Environment (RECETOX), Brno, Czech Republic

${ }^{g g}$ Mermayde, Bergen, The Netherlands

${ }^{\text {hh }}$ Leibniz Institute of Plant Biochemistry, Halle, Germany

${ }^{i i}$ Hammerbacher GmbH Consulting \& Facilitation, Osnabrück, Germany

${ }^{\mathrm{jj}}$ University of Gothenburg, Gothenburg, Sweden

${ }^{\mathrm{kk}}$ KOCMOC.NET Design Agency, Leipzig, Germany

${ }^{11}$ University of Bern, Bern, Switzerland

mm The University of Queensland, National Research Centre for Environmental Toxicology (Entox), Brisbane, Australia

${ }^{\mathrm{nn}}$ University of Campinas, Limeira, Brazil 


\begin{abstract}
SOLUTIONS (2013 to 2018) is a European Union Seventh Framework Programme Project (EU-FP7) that aims to deliver a solution-oriented conceptual framework for the evidence-based development of environmental policies with regard to water quality and its protection against contamination. This project will integrate innovative chemical and effect-based monitoring tools with a full set of exposure, effect and risk assessment models and strategies to assess abatement options. Uniquely, SOLUTIONS takes advantage of (i) expertise of leading European scientists of major FP6/FP7 projects on chemicals in the water cycle, (ii) access to the infrastructure necessary to investigate the large basins of the Danube and Rhine as well as relevant Mediterranean basins as case studies, and (iii) innovative approaches for stakeholder dialogue and support. In particular, the EU Water Framework Directive (WFD) Common Implementation Strategy (CIS) working groups, International River Commissions, and water works associations will be directly supported with consistent guidance for the early detection, identification, prioritization, and abatement options for chemicals in the water cycle. A set of predictive models and tools will support stakeholders' management decisions by benefiting from the wealth of data generated from monitoring and chemical registration. SOLUTIONS will provide a specific emphasis on concepts and tools for the impact and risk assessment of complex mixtures of emerging pollutants, their metabolites and transformation products. Analytical and effect-based screening tools will be applied together with ecological assessment tools for the identification of toxicants and their impacts. Beyond state-of-the-art monitoring and management, tools will be elaborated allowing risk identification for aquatic ecosystems and human health. The SOLUTIONS approach will provide transparent and evidence-based suggestions of River Basin Specific Pollutants for the case study basins and support future review of priority pollutants under the WFD as well as potential abatement options.
\end{abstract}

\title{
1. Introduction
}

"Water is not a commercial product like any other but, rather, a heritage which must be protected, defended and treated as such." This claim by the EU Water Framework Directive (WFD) of water as a key resource for ecosystems and human life is still in contrast with an often poor ecological status in many European rivers and lakes. The Blueprint to Safeguard Europe's Water Resources (European Commission, 2012a) and the Commission assessment of the Member States River Basin Management Plans (RBMPs) (European Commission, 2012f) states that good ecological status is currently achieved in only $43 \%$ of the reported freshwater bodies and even the additional measures included in the plans are not expected to increase this to over $53 \%$ by 2015 . Previous projects have shown that chemical contamination may have significant effects on aquatic ecosystems (Hein et al., 2010). However, the assessment of chemical status indicates that a large proportion (about 40\%) of the EU water bodies have an unknown status due to insufficient monitoring in many Member States. Still, the monitoring programs initiated under the WFD have accumulated vast amounts of data on contamination and on the ecological status of surface waters in the EU (European Environment Agency, 2012). At the same time, a wealth of chemical property and environmental data from registration of chemicals (e.g. REACH (European Chemical Agency, 2014), biocides (European Commission, 1998), plant protection products (European Commission, 2009) and pharmaceuticals (European Commission, 2010)) is gradually becoming available. Although toxic effects on aquatic life are regularly observed, it remains a great challenge to link occurrence of chemicals with the ecological status of waters, to identify major chemical stressors that would call for management, and to find efficient solutions for the abatement of pollution-related risks. Typically, complex mixtures of priority pollutants, emerging substances, byand transformation products, and natural compounds co-occur in aquatic systems, thus rendering a comprehensive assessment challenging. Emerging substances include a multitude of polar and even ionic compounds for which many of the models developed for classical non-polar persistent organic pollutants (POPs) do not apply. Exposure resulting from direct emissions by point sources and by diffuse sources such as remobilisation from contaminated sediments, groundwater input, soil run-off, or atmospheric deposition is variable in time and space. Pollution may affect a multitude of targets in organisms, populations, and communities. The sheer number of potentially harmful chemicals challenges chemical monitoring and consequently there is a good chance that adverse impacts from unknown or unexpected chemicals and mixtures on aquatic communities and human health remain 
unrecognised. The problem is aggravated by analytical detection limits that may be too high for detecting chemicals below their predicted no-effect-concentrations (PNEC). There is also a lack of understanding regarding sources, transport pathways, transfer times, fate, and mixture effects, together with insufficiently developed modelling capacity. Finally, a better understanding is required of how to link early biological responses to chemical exposure detectable in bioassays and biomarkers to ecological responses at the population and community level (Ankley et al., 2010; Segner, 2011).

The EU-FP7 project SOLUTIONS is addressing these challenges by developing approaches to alleviate and prevent chemical pressures on Europe's water bodies and to strive for the goals of the WFD. These approaches are designed as interactive processes between hazard identification efforts and problem solving options (National Research Council, 2009) and by continuously involving stakeholders as well as a think tank. SOLUTIONS will help to develop a harmonised and transparent procedure for setting up lists of candidate River Basin Specific Pollutants (RBSPs) in support of the ecological status assessment, and will further support the review and update of the list of WFD priority substances that applies in chemical status assessment (European Commission, 2013). This goal requires improved procedures for the identification and prioritisation of emerging pollutants, and the development of new criteria and predictive tools for new and unrecognised pollutants, together with scientifically sound assessments of mixtures and options for their management. To this end, SOLUTIONS combines, integrates and validates monitoring- and modelling-based approaches and evaluates potential opportunities for improved coherence between water quality regulation (WFD and Drinking Water Directive) and regulations for market authorisation such as REACH.

Biological responses and chemicals will be identified with tools that are not based on pre-conceptions of effects or compounds present. At present, the focus is often on pre-selected biological endpoints and targeted compounds with the aim of defining the specific toxic burden of aquatic ecosystems and for human health. SOLUTIONS has the vision of understanding the overall and cumulative ecological and human health impact of all chemical substances relevant for European water resources, which will also address also the objectives of the Blueprint to Safeguard Europe's Water Resources whose time horizon is closely related to the EU's 2020 Strategy, the European Innovation Partnership on Water (European Commission, 2012c) and the Joint Programming Initiative "Water challenges for a changing world" (Water JPI, 2014).

\section{Objectives}

The SOLUTIONS project supports the overall aim of protecting European water resources and of identifying, assessing and prioritising emerging pollutants that might pose risks to aquatic ecosystems and related human health issues. To this end SOLUTIONS has the following scientific objectives:

The project intends to develop a novel conceptual framework for the prioritisation of pollutants for ecological and human health risk assessment and the abatement of toxicant mixtures in European water resources. This framework will be based on the alignment of field observations, made without pre-conceptions, with exposure and mixture impact predictions for chemicals that are known to be emitted, also considering abatement options. By including possible emerging contaminants of the future, using scenarios on economic, technological, demographic, climate and other developments, SOLUTIONS will address legacy, present and future pollution (Figure 1). This concept will help identify the strengths and weaknesses of field observations and modelling approaches, and will provide guidance for optimal mutual integration. The conceptual framework is to be developed in dialogue with key stakeholders from the regulatory and industrial community.

SOLUTIONS will also deliver efficient tools for the identification of substances and mixtures that pose risks to the aquatic environment and human health. The project sets out to develop a new generation of monitoring approaches and tools for the early detection and identification of harmful substances. These tools comprise sensitive methods for the analysis of pollutants at concentrations below their PNECs and to address impacts on ecosystems and human health, including targeted and novel, balanced effect-based tools (EBTs) as well as trait-based indicators of ecological impacts. It will further develop and improve integrated tools to characterise cause-effect relationships. A further intention is to support decision making in environmental and water policies by improving our 
understanding and capacity for exposure, effect and risk modelling by compiling a chain of conceptually integrated models and databases accessible via a user-friendly computer tool (RiBaTox). This includes spatially and temporarily resolved models of emissions, transport pathways as well as impacts and risks of emerging pollutants and transformation products including any combined effects occurring. The models will exploit monitoring and project data on a local, regional and European scale and make use of the wealth of data from the authorisation of plant protection products, biocides, pharmaceuticals, and registration of industrial chemicals under REACH.

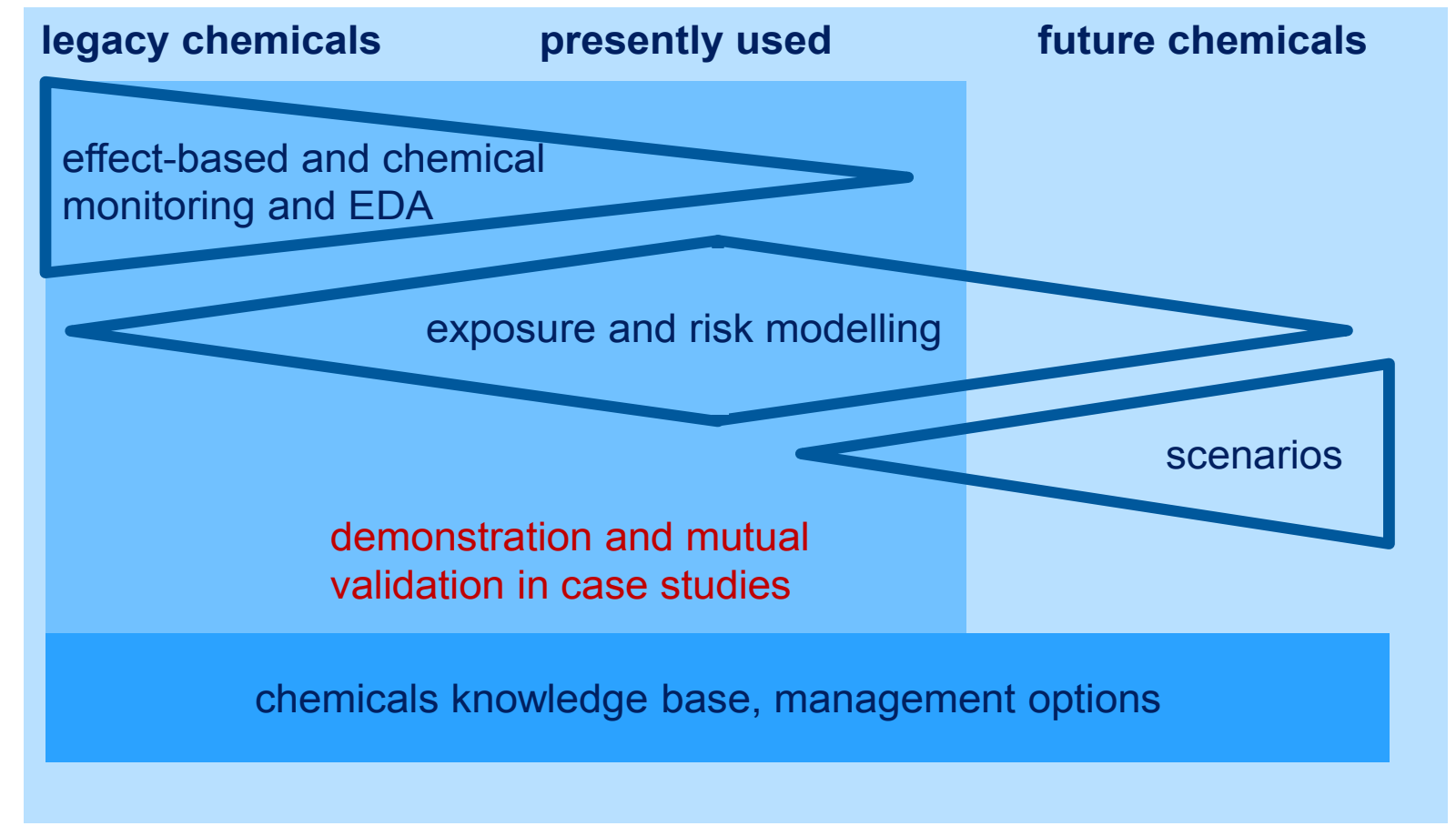

Figure 1: Complementary application of SOLUTIONS techniques to address the changing world of chemicals. EDA: Effect-directed analysis.

SOLUTIONS will evaluate the implications of the new tools and approaches for the overall assessment of the ecological and human health risks potentially associated with emerging substances in the (aquatic) environment. The project plans to demonstrate the added value of the new generation of tools in trans-European case studies in the Danube, Rhine, and rivers of the Iberian peninsula with links to existing monitoring programs such as the Joint Danube Survey 3 (JDS 3) (ICPDR, 2009) and links to projects on additional water treatment technologies at waste and drinking water utilities in the Rhine. The modelling and field-based approaches will be validated and applied to impact and risk assessments, the identification of RBSPs, and the evaluation of abatement options. SOLUTIONS will also evaluate potential opportunities and obstacles for coherence between the WFD and other existing policies (e.g. REACH). To analyse the legal basis for an integrated approach, we will address conflicting goals, e.g. between harmonization and more targeted assessment requirements of human health and environmental risks.

Finally, the project aims to provide new approaches for the prioritisation, assessment, management, and abatement of emerging pollutants, as well as a common knowledge base for a wide range of toxicants. To meet these objectives SOLUTIONS will synthesize the knowledge and novel tools, condense them into user-friendly guidelines, computer tools, and recommendations for direct support of the implementation of the WFD and for safe drinking water supply. The project will study abatement options and control measures for emerging pollutants in waste and drinking water treatment for effective risk reduction. This includes assessments of costs, benefits, and limitations of policy options, technical and non-technical measures, and proposals on innovative management methods. Extrapolation on a European scale will support the evidence-based review of priority substances under the WFD. Based on trends and scenarios identified, possible pollutants of tomorrow and related risks will be estimated involving a think tank of external experts and SOLUTIONS scientists. The projections will be combined with modelling to develop future scenarios of chemical risks, and to identify upcoming demands in environmental monitoring, assessment and management activities. 


\section{Conceptual Framework and Work Flow}

The proposed conceptual framework addresses major challenges of current water quality management which will be tackled with methods and approaches developed within the SOLUTIONS project. At the same time this forms the basis of the decision support tool RiBaTox as one of the major products of SOLUTIONS. The decision system offers four entry points that correspond to distinct stakeholder perspectives. A display of this framework, which is still under discussion with the stakeholders, is shown in Figure 2. The first entry point, representing the chemicals and mixtures produced, in use or predicted for use in Europe, addresses questions relating to the environmental behaviour and risk of these chemicals. The second entry point stands for the environmental status as determined by monitoring activities including contamination, measured toxic effects as well as the ecological status. The most prominent task of SOLUTIONS is to bring together chemicals and environmental status by advanced monitoring and modelling, in order to provide solutions for the key question of how best to identify and prioritise pollutants on the river basin and European scale. The third entry point relates to considerations of abatement options. SOLUTIONS will put a major emphasis on the evaluation of abatement options and criteria with respect to the environmental status as well as for specific chemicals and mixtures. The fourth entry point is societal developments representing the broad range of trends and decisions in society and policy as reflected e.g. in environmental regulation, which will influence the production, use, emission, and environmental management of chemicals. These developments are relevant for SOLUTIONS with regard to the analysis of policy instruments as well as for the prediction, prioritization and minimization of future risks using scenarios. Thus, SOLUTIONS wants to contribute to use and management of chemicals that is sustainable with respect to providing good water quality now and in the future and offers its support for the optimisation of legal and policy instruments in this field.

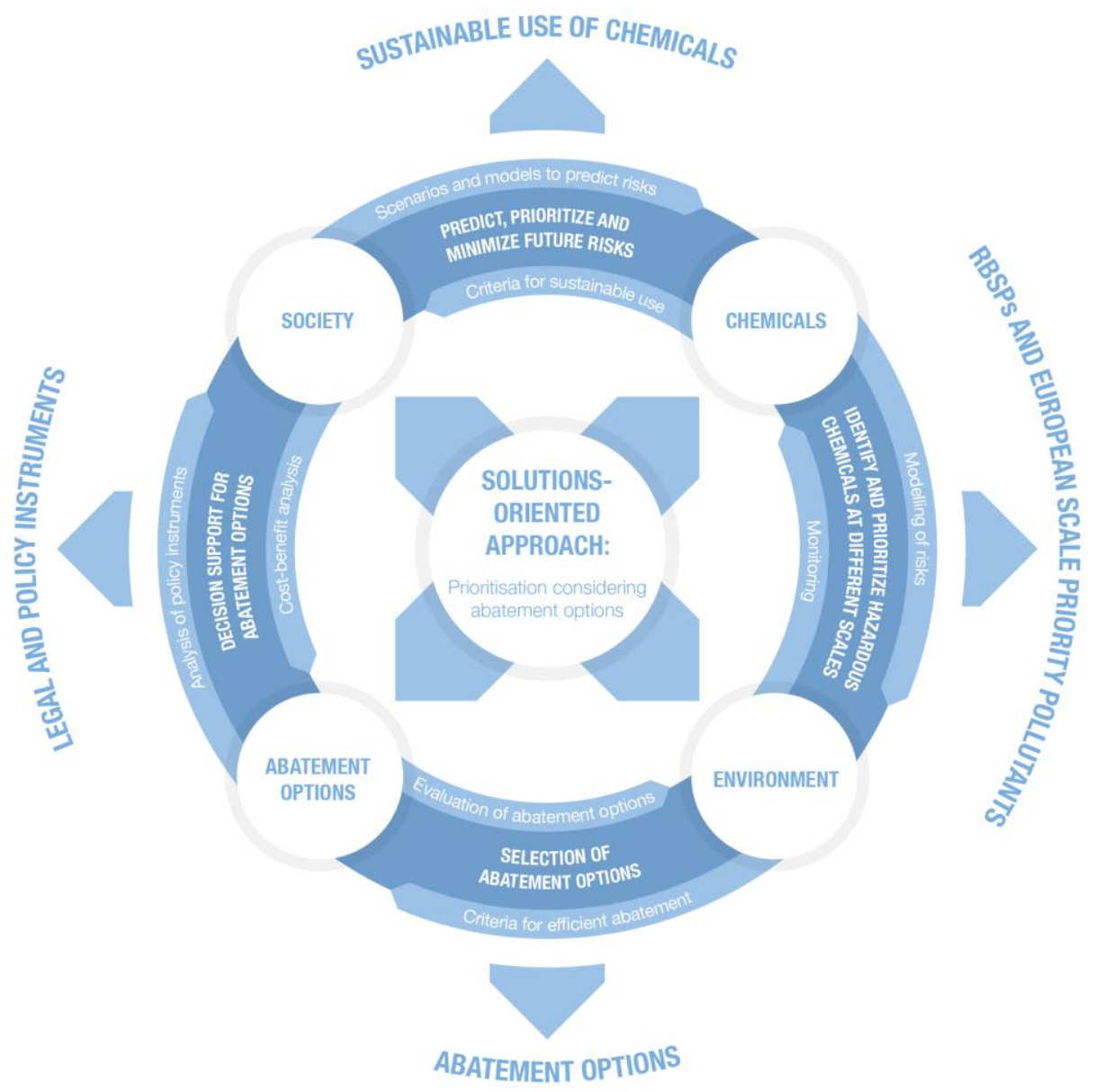

Figure 2: Scheme of conceptual framework of SOLUTIONS as a basis for the design of RiBaTox (the River Basin Toxicology meta-model) to support decision makers in water and chemicals management 
SOLUTIONS is structured into 4 sub-projects, which emanate from the work flow illustrated in Figure 3 that will be operational for the next five years. Sub-project SP1, focussing on Concepts \& Solutions, provides the framework for the entire project, refines the anticipated outcomes and facilitates the dialogue with stakeholders in order to make sure that the project remains focussed on providing solutions for major problems of emerging chemicals in water resources management. SP1 thus guides the sub-projects SP2 (Tools), SP3 (Models), and SP4 (Cases) which develop most of the necessary tools, models and data that need to be integrated and digested to provide the required solutions. These major products include the overall conceptual framework operationalized as a computer tool, called RiBaTox (River Basin Toxicology meta-model), to support the assessment, prioritisation and abatement of emerging chemicals, an advanced methodology for the prioritisation of (emerging) contaminant mixtures and innovative toxicant management focusing on abatement options for emerging contaminants and mixtures thereof. The science-policy interface will make the project results relevant for stakeholders, namely first and foremost the European Commission, International River Basin Commissions and drinking water associations. RiBaTox will be designed to support endusers in selecting and applying the appropriate tools and models developed, and data-mining the toxicant knowledge base that will compile, integrate, and digest compound-specific information in support of environmental assessment and management. Since regulations and technological development typically are investments into the future and should be robust under changing conditions, SOLUTIONS also addresses pollution problems of the future on the basis of scenarios and mobilises transdisciplinary expertise in a think tank of internal and external experts. Policy conflicts and gaps that might hamper the implementation of solutions to pollution problems will also be addressed. Specific efforts are made to coordinate the stakeholder dialogue and dissemination.

By using the concepts emanating from SP1, the two main approaches for prioritisation and risk assessment of mixtures of pollutants, monitoring and modelling, will be developed in SP2 (Tools) and SP3 (Models). In SP2 advanced chemical and effect-based tools for field-based assessments of water bodies and whole river basins will be developed and evaluated for implementation in environmental monitoring and assessment. SP2 will deal with the need of identifying previously unrecognised pollutants by adopting holistic approaches, including chemical analytical screening tools, effectdirected analysis and biological effect-based tools. Ecological approaches such as trait-based methods to link toxicological findings to adverse ecological outcomes will also be employed. All tools will be tested in the case studies and this will form the basis for assembling a guidance document. 


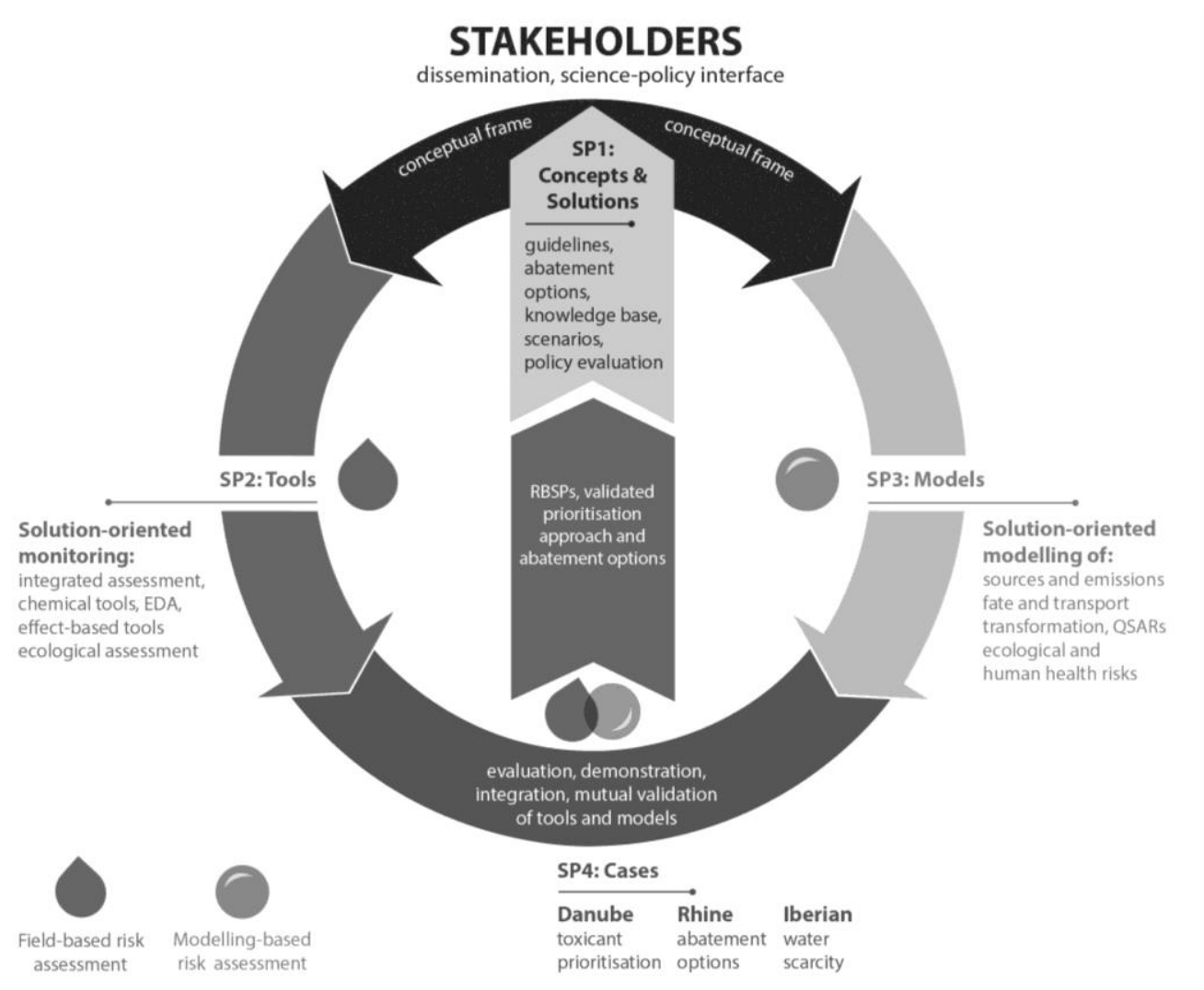

Figure 3: SOLUTIONS work flow and sub-projects

In SP3 a conceptually integrated set of predictive models will be developed and applied to compound and system-specific data for risk prediction on a European scale. Integrated models will comprise sources and emissions, fate and transport, substance environmental transformation and metabolism physico-chemical properties as well as human and ecological risk modelling of pollutant mixtures. Modelling approaches (SP3) and field-based assessments (SP2) support each other, e.g. by involving quantitative structure activity relationships (QSARs), predictive mixture toxicity and fate models in toxicant identification and effect analysis on the one hand, and contamination and effect observation for model validation on the other hand. The two approaches will be applied, evaluated and validated against each other in selected case studies (SP4 Cases), which will focus specifically on the identification of RBSPs and on the efficiency of abatement measures. Ultimately, a refined integrated framework for pollutant prioritisation and improved risk assessment will be developed and translated into guidelines and recommendations to support water policies (SP1).

\section{Approach}

The features of the SOLUTIONS conceptual framework comprise the following novel and innovative approaches:

Solution-oriented approaches that consider abatement options already for assessment and prioritisation. Risk assessment is often a purely scientific procedure that does not result in prioritisation or risk management measures, even after lengthy hazard and risk characterization efforts (National Research Council, 2009). This is due to knowledge gaps at any point of the process that may create barriers for completing the risk assessment procedure. To deal with such barriers, our solutionoriented approach will consider management options and stakeholder and regulatory problems already at the problem-formulation stage rather than only at the final step. Abatement options will be taken into account right from the beginning in order to achieve options for enhancement of water resources quality with limited resources.

Integration of human health and ecological risks. Human health and ecological risks are typically assessed separately and according to different concepts. The SOLUTIONS framework tries to link 
both domains on the basis of Modes of Action (MoA) information. The integrated view is also seen as a good basis to develop chemical footprints of the pollution of our water resources and assessment aggregation towards planetary boundaries. Different concepts will be combined by defining boundaries on the one hand according to current policy (Environmental Quality Standards (EQS), Good Ecological and Chemical Status, Tolerable Daily Intake (TDI)) as well as defined by (yet unknown) tipping points towards regime shifts in natural systems (Scheffer et al., 2009).

Integration of legacy, present use, and future chemicals. SOLUTIONS will strive to find adaptable solutions for assessment, prioritisation and abatement for legacy, present and future chemicals in the aquatic environment. To this end, the project combines monitoring-based approaches for chemicals that are already in the environment, exposure and effect modelling for compounds that are produced, applied and probably emitted to the environment, and scenarios to identify future trends in pollution.

Integration of modelling approaches, chemical analytics, and effect-based tools. Cause-effect directed monitoring and modelling-based approaches have distinct advantages and limitations, both for single substances and mixtures. SOLUTIONS will seek their integration and complementary use by including integrated testing strategies (ITS) and different available extrapolation tools. Options for reconciling model-based prospective and observation-based site specific assessments will be evaluated as a way to overcome limitations in data availability. Approaches for bridging the gap between singlespecies toxicity of mixtures and ultimate effects on the ecosystem level will also be considered. Tiered approaches will be employed to provide a flexible approach, with lower tiers for screening, and higher tiers for refined assessments, when needed.

Improved identification of emerging pollutants and hazardous transformation products. Novel screening techniques for large numbers of chemicals will be developed, with the aim of avoiding undue focus towards well-known and characterised pollutants (Krauss et al., 2010). To this end, both sensitive target monitoring of known contaminants and non-target screening of unknowns will be considered and integrated with effect-based monitoring. The novel approaches will facilitate the consideration of new substances, which have been excluded due to data gaps so far, in ranking procedures.

Identification of priority mixtures. The Scientific Committees of the European Commission have emphasised the need for the identification of priority mixtures (European Commission, 2011). A number of criteria were proposed for consideration, including indicators for similar toxic action, cooccurrence at individual substance concentrations close to acceptable levels, or potential for toxicological interactions between mixture components. SOLUTIONS will explore options for the practical application of such criteria, and the outcome will be integrated into the advanced framework for prioritisation.

Identification of drivers of mixture toxicity. Despite the presence of thousands of compounds in environmental mixtures, theoretical considerations and experimental findings suggest that the overall risk may often be governed by only a few key components of mixtures. The European Commission therefore considers the development of methodologies for the identification of such drivers of mixture toxicity as a research priority (European Commission, 2012b). SOLUTIONS will respond to this demand by exploring the applicability of both model- and effect-based approaches to this issue. The analysis will consider aquatic organism, aquatic ecosystems, and potential effects in humans via drinking water supply and fish consumption. Prioritisation concerns not only the mixture components that drive the risk in generic scenarios, but also site-specific exposures and potentially affected species. Some sites and species are likely to be affected more than others, due to local conditions and specific species- and assemblage vulnerability characteristics.

A prioritisation process taking into account existing knowledge gaps as a way to highlight priorities for research. The prioritisation framework to be developed within SOLUTIONS will seek to manage substances based on all available information, thereby avoiding the exclusion of substances for reasons of limited data. The prioritisation framework will build on the approach used by the NORMAN network on emerging substances (NORMAN, 2014; von der Ohe et al., 2011) in order to allow systematic identification and categorization of chemical substances for which action is needed as a matter of priority for reduction, monitoring of their emissions, but also for the gathering of additional scientific and technical data for improved assessment of their risks. It will be an iterative process 
integrating periodic revision of the priority substances within each "action category", whenever e.g. new information / more reliable data are generated or feedback from applied abatement measures is available for the revision process.

Consideration of technical and non-technical abatement options. The developed conceptual framework will help to evaluate the merits of technical end-of-pipe options such as quaternary wastewater treatment or separate treatment of special waste at the source against non-technical options such as education of producers, distributors and consumers, substitution of hazardous chemicals, application restrictions and harmonized take-back schemes for unused chemicals. The dependency of the treatment efficiency on the physico-chemical properties of the substances is reviewed. Also, the optimal placement of technical abatement options given the (climate-variable) hydrological situation and the geospecific emissions is evaluated and rules of thumb are deduced. Two innovative concepts will be operationalized and applied to evaluate risks and abatement options: chemical footprint (Hitchcock et al., 2012; Sala and Goralczyk, 2013) and planetary boundaries (Rockström et al., 2009) and their interfaces (Posthuma et al., subm.; Zijp et al., subm.).

Synergies and conflicts between the WFD and other existing policies (e.g. REACH). An analysis of synergies and conflicts between existing policies, conventions and international agreements on chemicals with respect to water quality issues will be conducted to provide new insights into gaps and recommendations for new and innovative policy development. Potential benefits from increased transparency in data and exchange of information will be evaluated. The hypothesis is that an adaptation of political instruments can optimise the chances in achieving the WFD goals of good water quality on a larger scale.

Operationalisation of the conceptual framework in terms of an end-user friendly decision support tool (RiBaTox) and a toxicant knowledge base. Supported by a continuous stakeholder dialogue the decision support tool RiBaTox as the main access point to the outputs of SOLUTIONS as well as an extensive toxicant knowledge base, both directly interfaced with the Information Platform for Chemical Monitoring (IPCheM) data base developed by the JRC (European Commission), will eventually provide a long sought-after user-friendly support. Both interlinked tools will have the potential to support decisions in environmental water policies on prioritisation and solution-based risk assessment of emerging pollutants and their mixtures.

\section{Tools and models for the identification of hazardous substances and mixtures}

Key to the success of the SOLUTIONS approaches will be the development of a new generation of monitoring approaches and tools for the early detection and identification of hazardous substances. These comprise chemical analytical, effect-based and ecological assessment tools and different combinations thereof.

Some of the listed priority substances (European Commission, 2013) are currently difficult or impossible to detect in water at the level of their water EQS even with the most advanced analytical techniques without novel concepts in sampling and sample clean-up, which is why for some, biota EQS are listed. SOLUTIONS will address the challenge of low water EQS and will design an optimised work flow for low detection limits using passive sampling (Lohmann et al., 2012; Smedes et al., 2013), large volume in situ solid phase extraction (LV-SPE, (Schulze et al., 2012)), on-line size exclusion devices, and dynamic extraction applying High Performance Counter Current Chromatography (HPCCC) (Sutherland et al., 2013).

One of the major challenges in the assessment of complex environmental mixtures is the identification of those chemicals that contribute significantly to the observed effects. Effect-directed analysis (EDA) addresses this challenge and helps to identify unexpected compounds that may exhibit adverse effects on biota and human health (Brack, 2003). The core concept of EDA is to reduce the complexity of natural samples to less complex mixtures or individual compounds that can be isolated and identified. The methodology has been further advanced in NORMAN (Brack et al., 2012) and the FP7 Initial Training Network EDA-EMERGE (Brack et al., 2013). However, EDA has still significant limitations that will be addressed. These include (i) the number of endpoints available and applied in a smallvolume, high-throughput format, (ii) limitations in structure elucidation of polar unknown compounds 
requiring LC-MS based techniques, which are hampered by a lack of spectra databases and automatized strategies, and (iii) restricted application in monitoring due to laborious and timeconsuming procedures.

The intention is to develop a tiered protocol combining a novel approach of a "virtual" EDA on the basin scale with higher tier EDA at specific sites to confirm "virtual" EDA results and to identify unknown toxicants isolated by effect-directed fractionation with cutting edge structure elucidation techniques. Virtual EDA has been suggested as a concept (Eide et al., 2002). It is based on chemical analytical screening together with effect-based screening, and attempts to reduce mixture complexity by multivariate statistical approaches to isolate those analytically separated mixture components that correlate with specific effects. Identification efforts can then be focused on these components. Also, the disparities between chemical and effect based assessments (Escher et al., 2014; Escher et al., 2013; Vermeirssen et al., 2010) might be reduced by extending the panel of receptor- and cell-based reporter assays into effect detectors for effect-directed analysis and targeted mixture effect investigations. These will comprise of already available tools such as gene reporter assays for endocrine or aryl hydrocarbon receptor (AhR) mediated responses or cell-based stress response assays. In addition to assays based on responses at the receptor level, we will exploit adaptive stress response pathways as early indicators of exposure to chemicals (Simmons et al., 2009). The broad array of toxicological endpoints in standardized and innovative small scale high-throughput assays, together with cutting edge multi-endpoint screening tools such as multi reporter gene cell assays (Zhang et al., 2011), a battery of diagnostic strains for mutagenicity detection (Umbuzeiro et al., 2011), adaptive stress response pathways and unbiased toxicogenomics (Williams et al., 2011), will extend the use of bioanalytical detectors in EDA significantly. This will create the opportunity to detect and identify pollutants that might cause harmful ecological impacts beyond the scope of current toxicant identification efforts. Toxicant identification will furthermore combine retention and fragmentation prediction with effect prediction using latest QSAR and read-across technology for the selection of candidate structures that match with analytical behavior and observed effects.

Chemical monitoring of water quality allows for quantitative assessment of the occurrence and fate of contaminants in water bodies and readily provides a management perspective regarding defined compounds. The ultimate goal of water quality management under the WFD, however, is the attainment of good ecological and chemical status of a water body. Thus, compounds that are analytically not detected, e.g. transformation products, and mixture effects are challenges where it is suggested that employing bioanalytical tools will improve assessments (Escher et al., 2011). A variety of effect-based tools will therefore be advanced to various degrees of applicability. Thus, they could eventually complement efforts of chemical water quality monitoring (WFD CIS subgroup Chemical Monitoring and Emerging Pollutants (CMEP), 2014) The efforts comprise of (i) standard toxicological organism bioassays that detect apical responses in fish, daphnia and algae, (ii) cell- or other in vitro reporter assays that measure specific non-lethal or stress responses, and (iii) ecology-oriented bioindicators. The latter include biomarker responses in individuals, population responses or community function or assembly information. Complementary to bioanalytics targeted at specific molecular and cellular level responses, the approach comprises unbiased toxicogenomic experiments to capture and study the relevance of yet unaccounted-for responses. Through anchoring the variety of molecular responses via biomarkers in organisms in situ to apical adverse outcomes in algae, daphnia and fish, we will explore the usefulness of these technologies. Effect-based tools could possibly help to determine and monitor water quality either with respect to identifying priority groups of pollutants or with regard to identifying potentially affected biological targets (the WFD Biological Quality Elements, BQEs). 


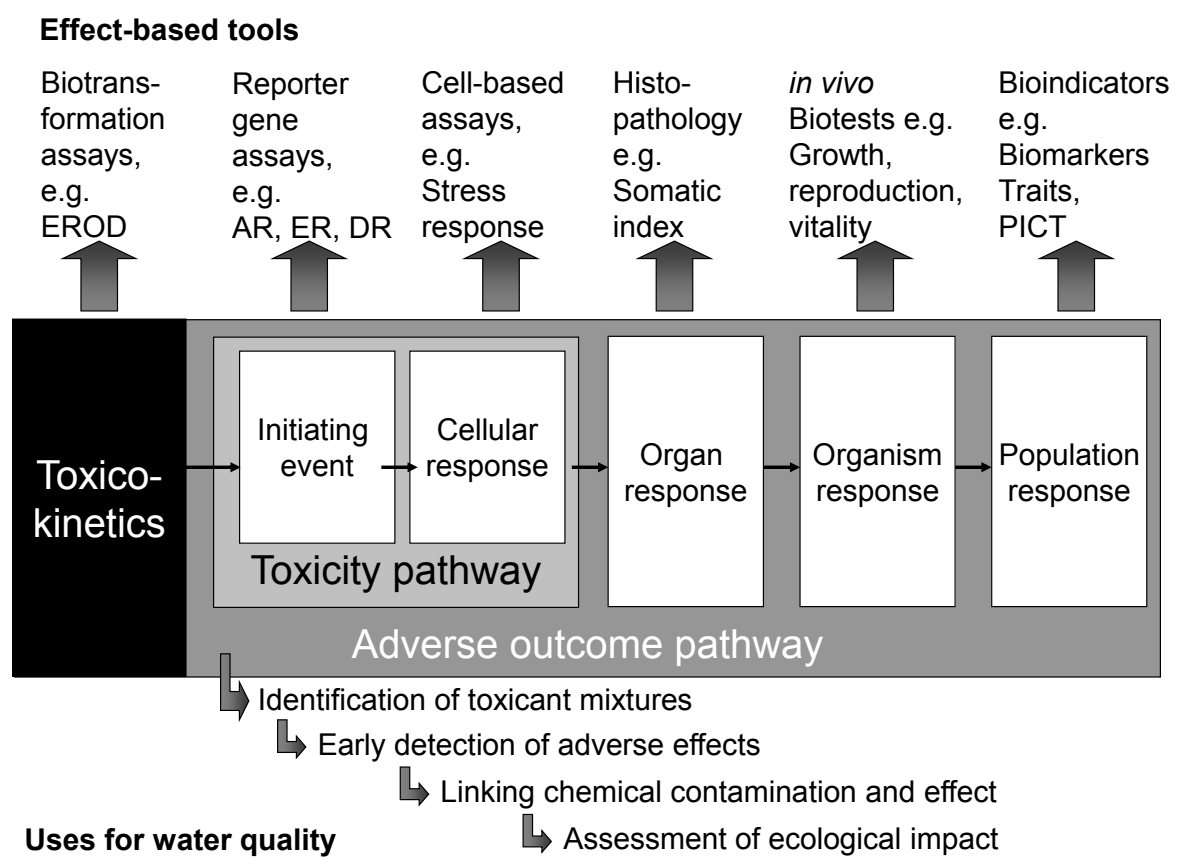

Figure 4: Utilising effect-based tools based on the concept of the adverse outcome pathways

The efforts will progress the role of EBTs for water quality monitoring through operationalization of the adverse outcome pathways (AOP) concept (Figure 4) (Ankley et al., 2010). By systematic attribution of information from different organisational levels (e.g. molecular, cellular, individuals and populations) scientifically credible links between the initial interaction of compounds with a biological target (the molecular initiating event) and the adverse outcome (e.g. at the individual or population level) can be established. AOPs will thus provide a framework in which the biological response detection tools at different level of biological complexity can be utilised for the different assessment questions. This will help to refine and streamline existing EBTs for monitoring regarding species and endpoint selection, extrapolation across chemicals, and prediction of mixture effects (Ankley et al., 2010).

Correlations between species traits and stressors will be studied under field and laboratory conditions. The linkage of trait responses to stressor gradients has the potential to expand biomonitoring approaches beyond traditional taxonomically based structure-oriented assessments that identify ecological effects. Traits-based information will help to provide more mechanistic linkages of biotic responses to environmental conditions, higher consistency in descriptors or metrics across broad spatial scales, and more seasonal stability compared with taxonomic measures, and finally improved integration of traits-based analysis into assessment programs (Van den Brink et al., 2011). Pollutioninduced community tolerance (PICT) (Blanck, 2002) has been validated in a broad range of studies and has been suggested as a community-oriented monitoring approach within the context of the WFD (Pesce et al., 2010). In order to develop PICT into a widely applicable tool for the effect based monitoring of chemical pollution SOLUTIONS will analyse the specificity of the PICT signal under complex pollution with respect to compounds with a similar ecological mode of action sharing the same uptake pathway, the same molecular mechanism of action or the same detoxification mechanism. If successful, PICT may provide causal links between the sensitivity profile of an algal community sampled from a field site and the presence of cocktails of hazardous chemicals.

Complementary to monitoring tools SOLUTIONS efforts will strive to improve our understanding and capacity for modelling exposure, effect and risk that can be used for site specific assessment. To this end a full chain of conceptually integrated models and databases is planned to be established. Risk modelling will follow a common tiered framework for human and ecological risk assessment to investigate whether mixtures of pollutants detectable in fish from EU river catchments are above concentrations that pose a risk for fish populations and human consumption. Ecotoxicological risk assessment will expand these analyses to entire species assemblages for all WFD BQEs and combined effects of pollutants on aquatic ecosystems and food webs. Population responses will be modelled 
using generic unstructured ordinary differential equations (ODE) models to identify typical species composition in specific river stretches together with information about chemical exposures followed by individual based models (IBMs) based on species traits. It will further be explored whether toxicity data gaps can be bridged by potency estimates derived from the concept of thresholds of toxicological concern (TTC), both for human health and ecological assessments, and how knowledge about drivers of mixture effects can improve risk management and prioritisation for emerging pollutants. Therefore, existing QSAR models for predicting (eco)toxicity will be improved by applying reference model predictions and data complemented using linear solvation energy relationships (LSER)-modelled baseline toxicity and automatized atom-centred fragment (ACF)-based read-across methodology (Kühne et al., 2013) in combination with a decision tree approach.

The human and ecological risk assessment within the project will be driven by integrated emission, fate and transport modelling, supplemented by new methods for the prediction of partitioning and transformation processes of emerging compounds. Considering a cascade of transformation processes for different types of chemicals will allow an advanced simulation of degradation processes and the prediction of possible transformation products of emerging compounds in the case studies.

The commonly applied and simplified steady-state tools used for fate and transport modelling of nonpolar organic substances will be upgraded to provide spatial and temporally-resolved simulations and provide mechanistic process-based modelling of a wider range of substances, including polar and ionic organic substances (Bouwman et al., 2012). This will be built on the growing availability of digital, high-resolution, spatially and temporally explicit data specifying the morphology, hydrology, geology and relevant socio-economic aspects on a European scale (Loos et al., 2009). It will integrate concepts or modules from open source software (e.g. GREAT-ER (Koormann et al., 2006), E-HYPE (Arheimer et al., 2008), GeoPearl (van der Linden et al., 2014), SWAT (SWAT, 2014)) into the modelling framework linking a set of state-of-the-art single-medium models for the atmosphere, the soil, groundwater, and surface water. The LSER models in fate and transport modelling will describe the partitioning of non-polar and ionic pollutants and simulate the fate and transport of emerging pollutants and their transformation products simultaneously. Simulated point and diffuse emissions of selected chemical pollutants will be used to model the transport and fate of these substances and their transformation products in the selected river catchments to evaluate and improve model components.

For emission modelling, SOLUTIONS will collect and estimate market and use volumes for chemicals, aiming to cover all chemicals that are currently marketed in the EU by combining data from existing registration data sources of various categories of potentially toxic chemicals: REACH (European Chemical Agency, 2014) registration data (industrial chemicals, biocides), pharmaceuticals (registration data on veterinary drugs), pesticides (HAIR, 2012) together with information on specific uses and releases of chemicals from existing data systems (e.g. EU ESPR database, Nordic SPIN database (KEMI Swedish Chemical Agency, 2014)). Existing release estimation methods (formerly used EUSES A- and B-tables, currently used REACH ERC and SPERC release fractions, HAIRsystem of pesticide release estimation, Nordic SPIN data system), will be tested with measured release and subsequently expanded to a generic emission modelling system, striving to achieve more realistic estimates of the fractions of chemicals released EU-wide to air, water and soil, building on and supporting further development of the WFD CIS Guidance (European Commission, 2012d).

SOLUTIONS will apply the models to as many substances and as many basins as possible in order to derive rapid assessment tools and meta-models, that allow capture of some of the variability of Europe's river basins. The full modelling framework will become available during the project duration for stakeholders to perform higher tier spatially and temporally explicit modelling.

\section{Demonstration in trans-European case studies}

The assessment of chemical status of the EU water bodies indicates that a large proportion (about $40 \%$ ) have an unknown status due to insufficient monitoring in many Member States (European Commission, 2012a; European Commission, 2012f). This situation also holds for the Danube, selected as one of the SOLUTIONS case studies (ICPDR, 2009). A 'rare-in-Europe' combination of data will be provided from the Danube river basin to validate all components of the integrated risk 
modelling; to explore cause-effect relationships; and to suggest RBSPs with respect to ecosystem and human health. SOLUTIONS has a unique opportunity to work with the most recent data on the pollution profile of this largest EU river basin obtained within the JDS3 sampling campaign in August - September 2013. In a wider perspective, JDS data will be exploited to support higher tier ecological risk modelling, addressing a multi-stressor situation. The project targets include suggesting a list of the Danube RBSPs together with their draft EQSs, which will be discussed with all stakeholders.

In most of the EU member states, centralized wastewater treatment represents a major source of emerging compounds, as has been shown by mass-flux analysis in various large scale studies on European and Asian river networks (Heeb et al., 2012; Ort et al., 2009; ter Laak et al., 2010), and these are therefore major targets for mitigation measures. A number of European utilities in Switzerland, Germany and the Netherlands among others are therefore reviewing or considering implementation of additional technologies to enhance the removal of emerging compounds in wastewater effluents. While technologies such as advanced oxidation or activated carbon treatment have been demonstrated as technically successful (Boehler et al., 2012; Hollender et al., 2009; Kovalova et al., 2013; Zimmermann et al., 2011), it is necessary to evaluate their influence on environmental impacts and on human health risks to justify such enormous investments. Pilot water treatment plants will allow the evaluation of abatement options with respect to removal of emerging pollutants and address human health relevant exposure pathways via drinking water and fish consumption including mixture toxicity considerations and options for data gap handling. Furthermore, additional technologies as being applied or considered for drinking water utilities are considered such as innovative membrane treatment or the effectivity of soil filtration. For the river Rhine catchment a comprehensive transnational cost-efficient placement strategy of abatement options to improve surface water quality will be developed. This effort will utilise results from SOLUTIONS case studies together with comprehensive hydrological modelling approaches combined with geospecific emission patterns. A tool-box of targeted chemical and toxicological methods for evaluation of abatement options with regard to ecological and human health will be proposed and made accessible via RiBaTox.

According to the Commission's Review of the Policy on Water Scarcity and Droughts (European Commission, 2012e) in 2007, at least $11 \%$ of the EU population and $17 \%$ of its territory had experienced water scarcity. Scenarios suggest that, in addition to severe flow alterations and imbalance between water availability and use, impacts on agriculture, tourism and industry, changes in biological communities, a decrease of nutrient uptake, primary production and decomposition, and increased concentrations of pollutants will occur (Green et al., 2013; Navarro-Ortega et al., 2012). Hence, water scarcity, enhanced by climate change, provides new challenges for maintaining a good water quality. Pesticides are detected at higher concentrations in Mediterranean rivers due to intensive agricultural activity. The ecological status is thus affected by a scarcity of water and high contamination, while wastewater and drinking water treatments are more challenging due to variable flows, the high complexity of the source water, and requirements of water re-use. These issues have currently been investigated in the Spanish project SCARCE (Navarro-Ortega et al., 2012), whose main objectives are to describe and predict the relevance of global change impacts on water availability, water quality and ecosystem services in Mediterranean river basins of the Iberian Peninsula, as well as their impacts on the associated human society and economy. Applying SOLUTIONS models and tools on the river basins Llobregat and Ebro; we seek to provide significant synergies with the SCARCE findings which offer a unique case complementary to the Danube and Rhine studies.

In all case studies SOLUTIONS will demonstrate and evaluate the new tools and models on the basis of the projects' conceptual framework for the assessment, prioritisation and abatement of complex mixtures of toxicants. Identification of 'relevant' pollutants, establishment of their toxic thresholds, and a clear assignment to their diffuse or point source release will be conducted. Sub-basin-specific emission inventories and extensive monitoring data will be used for the validation of models predicting impacts and risks. Simplified concepts of (mixture) toxicity prediction will be fieldvalidated.

\section{The SOLUTIONS consortium and stakeholder involvement}

The SOLUTIONS consortium consists of 39 partners (see list of authors) from eighteen different 
countries: twelve EU member states, three other European countries, plus three additional partners from Australia, Brazil, and China. Fourteen Universities and twelve national research centres form the SOLUTIONS institutional core group, but additionally nine commercial enterprises are involved. These comprise research and development companies as well as technical supply and consulting firms. Small and medium size enterprises play a prominent role in the SOLUTIONS consortium e.g. to head the sub-project on case studies, to develop and merchandise innovative technology and to organise the stakeholder dialogue.

The SOLUTIONS consortium comprises outstanding scientific expertise in advanced effect-based tools for ecological and human risk detection, including state-of-the-art in vitro assays and multiendpoint receptor gene assays and toxicogenomics, advanced in-vivo bioassays and biomarkers, and population and community level effect assessment tool. This assembly of biologically focused groups is complemented by the most advanced European analytical and EDA groups. Highly experienced groups in exposure and effect modelling of mixtures of emerging pollutants on different scales provide and bring together the models required for a better understanding of risks. The particularly strong cluster of groups in advancing concepts for chemical mixture assessment in SOLUTIONS is unique and promises significant progress in the development from individual compound based approaches towards an adequate reflection of complex mixtures in water policies. While the consortium compiles unique scientific expertise, it also addresses the science-policy interface and stakeholders through dialogue with key players in European and river-basin specific decision making and at the sciencepolicy interface.

In order to ensure that project outcomes and deliverables will actually meet the requirements of water and chemicals regulation and policy and also of water suppliers and other relevant industries, a stakeholder board has been established which already provided a list of stakeholder expectations. This board involves key regulators and end-users of results on the European level such as the DG Environment of the European Commission, the European Environmental Agency (EEA), the European Federation of National Association of Water and Waste Water Services (EUREAU), and the European network on emerging pollutants (NORMAN). At the same time leading national environmental agencies such as the German Federal Environmental Protection Agency (UBA), the Swedish Chemical Agency (KEMI) and the Catalan Water Agency (ACA) are involved. The International Commissions for the protection of the Danube River (ICPDR) and the Rhine (ICPR) are the partners that make sure that SOLUTIONS research in the case studies of the Danube and Rhine are recognized and critically discussed among decision makers and practitioners in these river basins. The board is complemented by Veolia Environment, a leading multinational company in water supply and management, as well as by the North-American governmental environmental agencies Environment Canada and US-EPA.

\section{Acknowledgments}

The SOLUTIONS Project is supported by the European Union Seventh Framework Programme (FP7-ENV-2013-two-stage Collaborative project) under grant agreement 603437.

\section{References}

Ankley GT, Bennett RS, Erickson RJ, Hoff DJ, Hornung MW, Johnson RD, et al. Adverse outcome pathways: A conceptual framework to support ecotoxicology research and risk assessment. Environmental Toxicology and Chemistry 2010; 29: 730-741.

Arheimer B, Lindström G, Pers C, Riosberg J, Strömqvist J. Development and test of a new Swedish water quality model for small-scale and large-scale applications. NHP Report. XXV Nordic Hydrological Conference (Reykjavik, 11-13 August 2008), 2008.

Blanck H. A critical review of procedures and approaches used for assessing pollutioninduced community tolerance (PICT) in biotic communities. Human and Ecological Risk Assessment 2002; 8: 1003-1034.

Boehler M, Zwickenpflug B, Hollender J, Ternes T, Joss A, Siegrist H. Removal of 
micropollutants in municipal wastewater treatment plants by powder-activated carbon. Water science and technology: a journal of the International Association on Water Pollution Research 2012; 66: 2115.

Bouwman AF, Bierkens MFP, Griffioen J, Hefting MM, Middelburg JJ, Middelkoop H, et al. Nutrient dynamics, transfer and retention along the aquatic continuum from land to ocean: towards integration of ecological and biogeochemical models. Biogeosciences Discuss 2012; 9: 8733-8782.

Brack W. Effect-directed analysis: a promising tool for the identification of organic toxicants in complex mixtures. Analytical and Bioanalytical Chemistry 2003; 377: 397-407.

Brack W, Dulio V, Slobodnik J. The NORMAN Network and its activities on emerging environmental substances with a focus on effect-directed analysis of complex environmental contamination. Environmental Sciences Europe 2012; 24: 29.

Brack W, Govender S, Schulze T, Krauss M, Hu M, Muz M, et al. EDA-EMERGE: an FP7 initial training network to equip the next generation of young scientists with the skills to address the complexity of environmental contamination with emerging pollutants. Environmental Sciences Europe 2013; 25: 18.

Eide I, Neverdal G, Thorvaldsen B, Grung B, Kvalheim OM. Toxicological evaluation of complex mixtures by pattern recognition: Correlating chemical fingerprints to mutagenicity. Environmental Health Perspectives 2002; 110: 985-988.

Escher B, Chapman HCON, Leusch F, Poulsen ACON. Bioanalytical tools in water quality assessment: International Water Assn, 2011.

Escher BI, Allinson M, Altenburger R, Bain PA, Balaguer P, Busch W, et al. Benchmarking Organic Micropollutants in Wastewater, Recycled Water and Drinking Water with In Vitro Bioassays. Environmental Science \& Technology 2014; 48: 1940-1956.

Escher BI, van Daele C, Dutt M, Tang JYM, Altenburger R. Most Oxidative Stress Response In Water Samples Comes From Unknown Chemicals: The Need For Effect-Based Water Quality Trigger Values. Environmental Science \& Technology 2013; 47: 70027011.

European Chemical Agency. REACH, http://echa.europa.eu/regulations/reach, 2014.

European Commission. Directive 98/8/EC of the European Parliament and of the Council of 16 February 1998 cocerning the placing of biocidal products on the market. Official Journal of the European Communities, 1998.

European Commission. Regulation (EC) No 1107/2009 of the European Parliament and of the Council of 21 October 2009 concerning the placing of plant protection products on the market and repealing Council Directives 79/117/EEC and 91/414/EEC. 2009.

European Commission. Directive 2010/84/EU of the European Parliament and of the Council amending, as regards pharmacovigilance, Directive 2001/83/EC on the Community code relating to medicinal products for human use, OJ L348, 31.12.2010; Regulation (EU) No 1235/2010 of the European Parliament and of the Council amending, as regards pharmacovigilance of medicinal products for human use, Regulation (EC) No 726/2004 laying down Community procedures for the authorization and supervision of medicinal products for human and veterinary use and establishing a European Medicines Agency, and Regulation (EC) No 1394/2007 on advanced therapy medicinal products, OJ L348, 31/12/2010. 2010.

European Commission. EC (European Commission - Directorate-General for Health \& Consumers - Scientific Committee on Health and Environmental Risks (SCHER), Scientific Committee on Emerging and Newly Identified Health Risks (SCENIHR) Scientific Committee on Consumer Safety (SCCS) (2011) Toxicity and Assessment of Chemical Mixtures (Final approved opinion), 2011.

European Commission. A Blueprint to Safeguard Europe's Water Resources, Communication from the Commission to the European Parliament, the Council, the European 
Economic and Social Committee and the Committee of the Regions, $\operatorname{COM}(2012) 673$ final., 2012a.

European Commission. The combination effects of chemicals - Chemical mixtures.

Communication from the Commission to the Council, $\operatorname{COM}(2012) 252$ final, Brussels, 31.5.2012, 2012b.

European Commission. Commission Communication on the European Innovation Partnership on Water, COM(2012) 216 final, 10.05.2012, 2012c.

European Commission. Common Implementation Strategy for the Water Framework Directive (2000/60/EC). Guidance document No 28. Technical Guidance on the Preparation of an Inventory of Emissions, Discharges and Losses of Priority and Priority Hazardous Substances 2012d.

European Commission. Communication from the Commission to the European Parliament, the Council, the European Economic and Social Committee and the Committee of the Regions report on the review of the European Water Scarcity and Droughts Policy, Com(2012) 672 final., 2012e.

European Commission. Report from the Commission to the European Parliament and the Council on the implementation of the Water Framework Directive (2000/60/EC) river basin management plans, report from the Commission to the European Parliament and the Council on the implementation of the Water Framework Directive (2000/60/EC) river basin management plans, $\operatorname{COM}(2012) 670$ final., 2012f.

European Commission. Directive 2013/39/EU of the European Parliament and the Council of 12. August 2013 amendin Directives 2000/60/EC and 2008/105/EC as regards priority substances in the field of water policy. Official Journal of the European Union 2013; L 226/1.

European Environment Agency. EEA State of Water report, http://www.eea.europa.eu/themes/water/publications-2012, 2012.

Green C, Williams R, Kanda R, Churchley J, He Y, Thomas S, et al. Modeling of Steroid Estrogen Contamination in UK and South Australian Rivers Predicts Modest Increases in Concentrations in the Future. Environmental Science \& Technology 2013; 47: 7224-7232.

HAIR. Harmonised environmental indicators for pesticide risk, http://www.hair.pesticidemodels.eu/home.shtml, 2012.

Heeb F, Singer H, Pernet-Coudrier Bt, Qi W, Liu H, Longrée P, et al. Organic Micropollutants in Rivers Downstream of the Megacity Beijing: Sources and Mass Fluxes in a LargeScale Wastewater Irrigation System. Environmental science \& technology 2012.

Hein M, de Deckere E, de Zwart D, Foekema EM, Marcomini A, Munoz I, et al. MODELKEY. Key findings and recommendations for reaching EU Water Framework Directive's quality objectives. Umweltwissenschaften und Schadstoff-Forschung 2010; 22: 217-228.

Hitchcock K, Panko J, Scott P. Incorporating chemical footprint reporting into social responsibility reporting. Integrated environmental assessment and management 2012; 8: 386-388.

Hollender J, Zimmermann SG, Koepke S, Krauss M, McArdell CS, Ort C, et al. Elimination of organic micropollutants in a municipal wastewater treatment plant upgraded with a full-scale post-ozonation followed by sand filtration. Environmental science \& technology 2009; 43: 7862-7869.

ICPDR. Danube River Basin District Management Plan, 14 December 2009, Accessible via http://www.icpdr.org/main/publications/danube-river-basin-management-plan, 2009.

KEMI Swedish Chemical Agency. SPIN, Substances in preparations in Nordic Countries. 2014, 2014.

Koormann F, Rominger J, Schowanek D, Wagner JO, Schroder R, Wind T, et al. Modeling the 
fate of down-the-drain chemicals in rivers: An improved software for GREAT-ER. Environmental Modelling \& Software 2006; 21: 925-936.

Kovalova L, Knappe DR, Lehnberg K, Kazner C, Hollender J. Removal of highly polar micropollutants from wastewater by powdered activated carbon. Environ Sci Pollut Res Int 2013; 9: 9.

Krauss M, Singer H, Hollender J. LC-high resolution MS in environmental analysis: from target screening to the identification of unknowns. Analytical and Bioanalytical Chemistry 2010; 397: 943-951.

Kühne R, Ebert R-U, von der Ohe PC, Ulrich N, Brack W, Schüürmann G. Read-Across Prediction of the Acute Toxicity of Organic Compounds toward the Water Flea Daphnia magna. Molecular Informatics 2013; 32: 108-120.

Lohmann R, Booij K, Smedes F, Vrana B. Use of passive sampling devices for monitoring and compliance checking of POP concentrations in water. Environmental Science and Pollution Research 2012; 19: 1885-1895.

Loos S, Middelkoop H, van der Perk M, van Beek R. Large scale nutrient modelling using globally available datasets: A test for the Rhine basin. Journal of Hydrology 2009; 369: 403-415.

National Research Council. Committee on Improving Risk Analysis Approaches Used by the U.S. EPA. Science and Decisions: Advancing Risk Assessment. Washington DC: The National Academic Press, 2009.

Navarro-Ortega A, Acuña V, Batalla RJ, Blasco J, Conde C, Elorza FJ, et al. Assessing and forecasting the impacts of global change on Mediterranean rivers. The SCARCE Consolider project on Iberian basins. Environmental Science and Pollution Research 2012; 19: 918-933.

NORMAN. NORMAN Association (Network of reference laboratories and related organisations for monitoring and bio-monitoring of emerging environmental substances), Working Group on Prioritisation of Emerging Substances. NORMAN Prioritisation framework for emerging substances. Unpublished Draft 2012 (Information available on the website www.norman-network.net), 2014.

Ort C, Hollender J, Schaerer M, Siegrist H. Model-based evaluation of reduction strategies for micropollutants from wastewater treatment plants in complex river networks. Environ Sci Technol. 2009; 43: 3214-20.

Pesce S, Lissalde S, Lavieille D, Margoum C, Mazzella N, Roubeix V, et al. Evaluation of single and joint toxic effects of diuron and its main metabolites on natural phototrophic biofilms using a pollution-induced community tolerance (PICT) approach. Aquatic Toxicology 2010; 99: 492-499.

Posthuma L, Bjorn A, Zijp MC, Birkved M, Diamond ML, Hauschild MZ, et al. Beyond a safe operating space: Finding chemical footprinting feasible. Environmental Science \& Technology subm.

Rockström J, Steffen W, Noone K, Persson Å, Chapin Iii FS, Lambin E, et al. Planetary boundaries: exploring the safe operating space for humanity. Ecology and Society 2009; 14: 32.

Sala S, Goralczyk M. Chemical footprint: A methodological framework for bridging life cycle assessment and planetary boundaries for chemical pollution. Integrated Environmental Assessment and Management 2013; 9: 623-632.

SCARCE. http://www.scarceconsolider.es/publica/P000Main.php, 2014.

Scheffer M, Bascompte J, Brock WA, Brovkin V, Carpenter SR, Dakos V, et al. Early-warning signals for critical transitions. Nature 2009; 461: 53-59.

Schulze T, Bahlmann A, Bustos PI, Hug C, Krauss M, Walz K-H, et al. Automatisierte großvolumige Festphasenextraktion (LVSPE) für das effekt-basierte Monitoring von Oberflächen-, Grund- und Abwässern. SETAC GLB poster 16632012. 
Segner H. Moving beyond a descriptive aquatic toxicology: The value of biological process and trait information. Aquatic Toxicology 2011; 105: 50-55.

Simmons SO, Fan CY, Ramabhadran R. Cellular Stress Response Pathway System as a Sentinel Ensemble in Toxicological Screening. Toxicological Sciences 2009; 111: 202225.

Smedes F, van Vliet LA, Booij K. Multi-Ratio Equilibrium Passive Sampling Method to Estimate Accessible and Pore Water Concentrations of Polycyclic Aromatic Hydrocarbons and Polychlorinated Biphenyls in Sediment. Environmental science \& technology 2013; 47: 510-517.

Sutherland I, Thickitt C, Douillet N, Freebairn K, Johns D, Mountain C, et al. Scalable Technology for the Extraction of Pharmaceutics: Outcomes from a 3 year collaborative industry/academia research programme. Journal of Chromatography A 2013; 1282: 84-94.

SWAT. Soil \& Water Assessment Tool, http://swat.tamu.edu/software/swat-model/. 2014. ter Laak TL, Tolkamp, H., Hofman, J. Geneesmiddelen in de Watercyclus in Limburg - Fase 1: Voorkomen, herkomst en ernst van geneesmiddelen in het watersysteem. KWR Watercycle Research Institute, Nieuwegein, The Netherlands, 2013, pp. 86.

ter Laak TL, van der Aa M, Houtman CJ, Stoks PG, van Wezel AP. Relating environmental concentrations of pharmaceuticals to consumption: A mass balance approach for the river Rhine. Environment international 2010; 36: 403-409.

Umbuzeiro G, Machala M, Weiss J. Diagnostic Tools for Effect-Directed Analysis of Mutagens, AhR Agonists, and Endocrine Disruptors. In: Brack W, editor. EffectDirected Analysis of Complex Environmental Contamination. 15, 2011, pp. 69-82.

Van den Brink PJ, Alexander AC, Desrosiers M, Goedkoop W, Goethals PLM, Liess M, et al. Traits - based approaches in bioassessment and ecological risk assessment: Strengths, weaknesses, opportunities and threats. Integrated environmental assessment and management 2011; 7: 198-208.

van der Linden T, van den Berg E, Leistra M, Tiktak A, Ktuijne R, Boesten J, et al. PEARL and GeoPEARL, http://www.pearl.pesticidemodels.eu/, 2014.

Vermeirssen ELM, Hollender J, Bramaz N, Van der Voet J, Escher BI. Linking toxicity in algal and bacterial assays with chemical analysis in passive samplers deployed in 21 treated sewage effluents. Environmental Toxicology and Chemistry 2010; 29: 25752582.

von der Ohe PC, Dulio V, Slobodnik J, De Deckere E, Kühne R, Ebert R-U, et al. A new risk assessment approach for the prioritization of 500 classical and emerging organic microcontaminants as potential river basin specific pollutants under the European Water Framework Directive. Science of the Total Environment 2011; 409: 2064-2077.

Water JPI. Water challenges for a changing world, http://www.wateripi.eu/water-jpi/, 2014.

WFD CIS subgroup Chemical Monitoring and Emerging Pollutants (CMEP). Technical report on aquatic effect-based monitoring tools, draft 2014.

Williams TD, Turan N, Diab AM, Wu H, Mackenzie C, Bartie KL, et al. Towards a System Level Understanding of Non-Model Organisms Sampled from the Environment: A Network Biology Approach. PLoS Comput Biol 2011; 7: e1002126.

Zhang X, Wiseman S, Yu H, Liu H, Giesy JP, Hecker M. Assessing the toxicity of naphthenic acids using a microbial genome wide live cell reporter array system. Environmental Science and Technology-Columbus 2011; 45: 1984.

Zijp MC, Posthuma L, Van de Meent D. Definition and first applications of a chemical footprint methodology. Environmental Science \& Technology subm.

Zimmermann SG, Wittenwiler M, Hollender J, Krauss M, Ort C, Siegrist H, et al. Kinetic assessment and modeling of an ozonation step for full-scale municipal wastewater treatment: Micropollutant oxidation, by-product formation and disinfection. Water 
research 2011; 45: 605-617. 